\title{
Diet adherence dynamics and physiological responses to a tomato product whole-food intervention in African-American men
}

\author{
Eunyoung Park ${ }^{1 *}$, Maria Stacewicz-Sapuntzakis ${ }^{2}$, Roohollah Sharifi ${ }^{3}$, Zhigang Wu ${ }^{3}$, Vincent L. Freeman ${ }^{4}$ \\ and Phyllis E. Bowen ${ }^{2}$ \\ ${ }^{1}$ Clinical Nutrition Research Center, Institute for Food Safety and Health, Illinois Institute of Technology, 10 West 35th Street, \\ Suite 3D6-1, Chicago, IL 60616, USA \\ ${ }^{2}$ Department of Kinesiology and Nutrition, University of Illinois at Chicago, Chicago, IL, USA \\ ${ }^{3}$ Department of Urology, University of Illinois at Chicago, Chicago, IL, USA \\ ${ }^{4}$ Department of Epidemiology and Biostatistics, University of Illinois at Chicago, Chicago, IL, USA
}

(Submitted 2 March 2012 - Final revision received 18 August 2012 - Accepted 23 August 2012 - First published online 19 November 2012)

\section{Abstract}

Tomatoes may have beneficial effects on prostate health. Efficacy trials would require long-term adherence to high levels of tomato product (TP) consumption. Therefore, factors that affect adherence in men most at risk and whether increased consumption of TP negatively affects diet and health are important concerns. Cancer-free African-American (AA) men ( $n$ 36) with mean serum prostate-specific antigen of 7.4 SD 5.6) $\mathrm{ng} / \mathrm{ml}$ were randomised to consume one serving of $\mathrm{TP} / \mathrm{d}$ or a control diet for 3 months. Mean intervention group lycopene intake rose to $464 \%$, with negligible control group increase. Plasma lycopene levels rose by 53 and $40 \%$ in the intervention group in months 1 and 3, respectively $(P<0 \cdot 0001)$, with no control group change. The intervention group's barriers to adherence score was inversely associated with both dietary $(r-0.49, P=0.02)$ and plasma lycopene concentration $(r-0.37, P=0.02)$. Their TP disadvantage score negatively correlated with the 3-month plasma lycopene concentrations $(r-0.37, P=0.008)$ and their weekly incentives and impediments were remarkably stable, 'concern for prostate health' being the most consistent over time. 'Liking tomatoes' and 'study participation' decreased in citation frequency at weeks 6 and 9, respectively. No major shifts occurred in dietary cholesterol or saturated fat, with no adverse effects on gastrointestinal complaints, serum total cholesterol, body weight or blood pressure. Lower socio-economic status AA men at higher prostate cancer risk can successfully achieve a whole food intervention goal with a corresponding rise in plasma lycopene concentrations, with no adverse effects on self-selected diet quality or health parameters.

Key words: Prostate cancer: Adherence: Tomato products: Lycopene

Widespread low adherence in diet intervention studies may be due to the complexity of the required change ${ }^{(1,2)}$. For example, an analysis of ninety-two independent fruit and vegetable intervention studies found that $75 \%$ of studies reported statistically significant increases in fruit and vegetable intake that averaged only 0.6 servings/d, a value far short of the goals in most of these studies ${ }^{(3)}$. Interventions that seek to change dietary patterns, a worthy goal for chronic disease prevention, make it difficult to unpack and study the dynamics of dietary adherence and non-adherence. Adherence may be better when people are advised to consume a single wholefood class as a beginning strategy and the dynamics of compliance should be simpler to interpret. Such studies have not been published, especially for vulnerable populations.

African-American (AA) men suffer the greatest proportion of health disparities of any studied category ${ }^{(4,5)}$, and adherence to advice among this group has been vastly understudied. Although there are several ongoing trials for behavioural change, either of diet or of lifestyle ${ }^{(6-8)}$, enrolment rates of $\mathrm{AA}$ men $(<25 \%)$ often provide insufficient numbers to evaluate adherence issues separately ${ }^{(9-13)}$. AA men are hesitant to participate in clinical trials or to adopt to medically related prevention approaches because of suspicion instigated from the widespread knowledge of the Tuskegee Institute Syphilis Trials ${ }^{(14)}$, mistrust of the medical community ${ }^{(15,16)}$, lack of access to medical care and concerns about screening and treatment ${ }^{(17)}$. Knowledge of low socio-economic status AA male recruitment, adherence, drop-out and join-in rates is necessary for robust clinical trial design.

AA men pose a special challenge for prostate health promotion because they have the world's highest incidence of prostate cancer (PC) along with a higher mortality rate ${ }^{(18)}$,

Abbreviations: AA, African-American; AICR, American Institute for Cancer Research; PC, prostate cancer; TP, tomato products.

*Corresponding author: E. Park, fax +1 312567 5321, email epark4@iit.edu 
and would benefit from robust, economically viable prevention strategies. One of the more promising whole-food candidates for PC prevention is tomato products (TP). A Food and Drug Administration systematic review of a submitted health claim for lycopene or tomatoes gave support for a modest preventive effect of tomato consumption for PC, although there was insufficient evidence for lycopene ${ }^{(19)}$. TP contain bioactive substances other than lycopene that may have cancerpreventive activity ${ }^{(20,21)}$, and studies using animal PC models found TP to be more protective than lycopene alone ${ }^{(22)}$. Whole-food PC intervention trials, such as those using TP, could only be accomplished by voluntary adherence through self-selection of a variety of TP in the open market. A wholefood intervention necessarily displaces other foods in the diet. TP (pizza, ketchup, spaghetti, chilli and tomato juice) have a reputation for being acidic, high in $\mathrm{Na}$ and are often served with cheese and/or meat high in cholesterol and saturated fat. Therefore, increased TP intake may have unintended public health consequences.

The aim of the study was to assess the feasibility of a TP intervention in older AA men with low socio-economic status, and to determine adherence factors and the incentives and impediments of doing so in the midst of their effort. Accompanying shifts in diet patterns that may affect CVD risk factors were also explored.

\section{Methods}

\section{Subjects}

Participants were AA men aged $\geq 45$ years, recently found to have serum prostate-specific antigen concentrations of $>2.5 \mathrm{ng} / \mathrm{ml}$, with negative prostate biopsy for PC. The Urology Clinic at the Jesse Brown Veteran's Administration Medical Center was the site of recruitment. Exclusion criteria were PC diagnosis, other cancers $<5$ years post-diagnosis, except for melanoma, already consuming five half-cup servings of $\mathrm{TP} /$ week.

The study was conducted according to the guidelines laid down in the Declaration of Helsinki, and all procedures involving human subjects/patients were approved by both the Institutional Review Board at University of Illinois at Chicago and the Research and Development Committee at Jesse Brown Veteran's Administration Medical Center. Written informed consent was obtained from all subjects. The study was conducted from June 2007 to August 2008 (ClinicalTrials.gov registration number: NCT01408459).

\section{Study design}

The study was a 3-month phase II, parallel-arm control group primary prevention study. The intervention was diet counselling to affect an increase in the consumption of TP in addition to the American Institute for Cancer Research (AICR) eating plan, which was provided to both the intervention and the control groups. Outcome assessments were blinded. Those who were willing and pre-eligible attended an initial screening visit to qualify them for the study, signed the consent, filled out a contact-demographic-environment questionnaire, had height and weight measured and were trained for the $24 \mathrm{~h}$ diet recall. Three additional telephone diet recalls were collected during the baseline period.

\section{The intervention}

AA men were randomised to either be coached to increase their TP consumption or to a control group receiving no TP coaching. After randomisation, each group attended their own orientation session that included a PowerPoint presentation that described PC, its incidence in AA men, how it developed and its risk factors. The control group session included dietary advice for cancer prevention based on the AICR eating plan. The intervention group session included the same description of PC, but in addition, the intervention group was provided with the scientific rationale for increasing $\mathrm{TP}$ in their diet to prevent PC along with the prescription to follow the AICR eating plan and to include at least one serving/d of TP in their diet. Standard serving sizes for various $\mathrm{TP}$ were provided. The sessions ranged from one to four participants, with an occasional spouse as recruitment proceeded. The intervention group also received individual weekly telephone coaching and colourful newsletters that contained (a) information about prostate health and its promotion, especially focused on AA male concerns, (b) information on tomatoes, (c) cartoons and jokes about tomatoes or prostate health and (d) TP recipes. The intervention group was sent home with six packs of V8 juice (low Na or regular, according to preference), lasagna noodles and two large cans of tomato sauce. The control group was sent home with four packs of apple or grape juice, and individual servings of canned fruit and boxes of raisins. Both groups were mailed six AICR brochures through the course of the 3-month intervention period. All participants made three clinic visits at baseline, 1 month and 3 months for blood samples, blood pressure, body weight and bioelectric impedance measurements and to fill out adverse symptoms forms.

\section{Assessment of factors affecting adherence}

A questionnaire was developed based on social cognitive theory that identified four domains that may modulate behaviour change: personal background (external, medical and knowledge), cognitive (self-efficacy, health belief and perceived susceptibility), social (support and reinforcement) and environmental (opportunities, e.g. barriers and food deserts) ${ }^{(23,24)}$. Study-specific items were constructed for each domain and incorporated into a questionnaire (described later) along with demographic information that might make an impact on adherence. Two identical questionnaires were constructed with certain items/scales modified to reflect the adherence assignment, TP consumption or AICR diet alone. These were administered after the orientation presentation but before the intervention commenced. In addition, shortterm effectors were assessed weekly during the intervention telephone call only. 


\section{Questionnaire development}

Before recruitment, eight AA men, in the same demographic as the target population, evaluated the screening demographic-health-environment questionnaire. It took the pre-validation respondents $10-15 \mathrm{~min}$ to complete the questionnaire. Responses from open-ended questions were categorised into fixed-choice scales for the final versions of the questionnaire. Of particular importance for the intervention group questionnaire were scaled questions for: (1) level of concern about PC, (2) level of belief that PC can be prevented, (3) knowledge of tomato-PC connection, (4) level of belief that $\mathrm{TP}$ can prevent $\mathrm{PC}$, (5) perceived ability to increase TP consumption, (6) social support and reinforcement, (7) environmental factors such as power over food choice, food purchasing and preparation and (8) intention to increase TP consumption. The control group questionnaire had the same questions that were directed towards increased fruit and vegetable intake and decreased meat and sugar intake. We were unable to perform statistical validation for internal consistency.

\section{Adherence assessment during the intervention}

The intervention group was contacted by telephone twice weekly for the first 2 weeks, then weekly for the next 2.5 months. A total of twelve $24 \mathrm{~h}$ diet recalls and weekly counts of TP intake were collected during the calls, along with the incentives and barriers to compliance encountered by the participants on the previous day. The telephone interview had three objectives: (a) to obtain detailed diet information for the previous day plus 1 week intake of TP and their type, (b) encountered incentives and impediments to the consumption of $\mathrm{TP}$ in the midst of the attempt and (c) coaching to improve and maintain adherence using motivational interviewing. Although men were coached to consume at least one $\mathrm{TP} / \mathrm{d}$, the study compliance standard was set at more than five servings/week. A serving was defined (for example) as a half cup of tomato sauce, two tablespoons of ketchup, a half cup of fresh tomatoes, a half cup of canned tomatoes or $6 \mathrm{oz}$ of juice containing 19.5, 5.1, 5.9, 11.6 and $16.4 \mathrm{mg}$ lycopene, respectively. The goal was to double the daily lycopene intake as a marker of TP exposure (we estimated an increase in intakes from $<5 \mathrm{mg}$ lycopene/d to a mean of $10 \mathrm{mg} / \mathrm{d}$ ) and also baseline plasma lycopene concentrations by $50 \%$.

Control group participants were called bi-weekly to obtain diet recalls (total of six recalls) and feedback on the usefulness of the pamphlets throughout the 3-month period. Fewer telephone calls to the control group were because of concern that a more active assessment might produce greater adoption of TP into their diet.

\section{Assessments of diet composition, gastrointestinal complaints and physiological changes}

Diet composition. The multiple-pass method ${ }^{(25,26)}$ was used by the interviewers, with the inclusion of weekdays and weekend days. The latest version of the Nutrition Data System for Research (Nutrition Coordinating Center, University of Minnesota, Minneapolis, MN, USA, 2008) was used to assess mean daily intakes of lycopene, other carotenoids, energy, saturated fat, cholesterol and food-based $\mathrm{Na}$. The $24 \mathrm{~h}$ recall technique was chosen because previous experience showed poor compliance with diet record keeping in this population and food checklists lacked sufficient specificity. The mean of four screening recalls was used as baseline and compared with the mean of twelve recalls for the intervention group and six recalls for the control group. Weekly tomato serving frequency was collected only from the intervention group, who were coached to perceive that the cause of success or failure was an important study objective.

Plasma lycopene concentrations. Total plasma lycopene levels were assessed by HPLC-UV/VIS (Waters Corporation) along with lutein, $\beta$-cryptoxanthin, $\alpha$ - and $\beta$-carotene, $\alpha$ and $\gamma$-tocopherol and retinol ${ }^{(20)}$. The peaks were detected by a Waters 490 Programmable Multiwave length Detector with four channels, each analyte at its specific maximum absorbance $(325 \mathrm{~nm}$ for vitamin A compounds, $295 \mathrm{~nm}$ for vitamin E compounds, $450 \mathrm{~nm}$ for carotenoids other than lycopene and $472 \mathrm{~nm}$ for lycopene). The detection limits were $0.5 \mathrm{~mm}$ for tocopherols, $3.5 \mathrm{~nm}$ for lutein and $9 \mathrm{~nm}$ for other carotenoids. The within-assay variability (CV) ranged from $1 \%$ for retinol and lutein to $7 \cdot 1 \%$ for $\alpha$-carotene and was $2.7 \%$ for lycopene. The between-assay $\mathrm{CV}$ ranged from $1.2 \%$ for retinol to $7 \cdot 4 \%$ for lycopene ${ }^{(27)}$. All samples from a single individual were measured within the same assay. We are a National Institute of Standards and Technology (NIST) reference laboratory for these carotenoids and participate in their quality assurance programme ${ }^{(28)}$.

Physiological changes. The following physiological changes were measured: body weight, percentage body fat, blood pressure, plasma lipids and glucose and gastrointestinal symptoms. Body fat percentage was measured by a Quantum Bioelectrical Impedance Analyzer (body composition analysis; RJL System) at all three visits. Plasma total cholesterol, HDL-cholesterol, LDL-cholesterol and glucose were measured by finger stick using the Cholestech LDX System (Cholestech Corporation) with test cassettes. Upper gastrointestinal symptoms were assessed by a standard gastrointestinal tract symptom checklist ${ }^{(29)}$, as TP are on the list of foods to avoid for lower oesophageal reflux. Briefly, the upper gastrointestinal symptoms questionnaire included questions about the severity of gastrointestinal symptoms during the last 4 weeks, rated $0-6$, where 0 meant 'no complaints' and 6 represented the worst imaginable severity of that symptom.

\section{Data analysis}

With fifteen men per group, the estimate to detect differences between groups with a power of $80-97 \%, P<0.5$ were as follows: $22 \%$ for plasma lycopene concentrations ${ }^{(30)}, 10 \%$ for systolic and $12 \%$ for diastolic blood pressure ${ }^{(31)}$ and $22 \%$ for plasma cholesterol concentrations ${ }^{(32)}$. The SAS statistical package (version 9.1; SAS Institute, Inc.) was used for all statistics. Differences in demographic and clinical characteristics 
between the intervention group and the control group were assessed by using the $\chi^{2}$ test for categorical variables or by using the $t$ test for continuous variables. The monthly responses of each group (intervention and control) were compared. Endpoints not conforming to expected distributional assumptions were log transformed and noted accordingly.

Because all men in the intervention group met the $a$ priori standard of $10 \mathrm{mg}$ lycopene intake per d, we were unable to divide them into adherer and non-adherer groups as planned. Therefore, an arbitrary division point of $18 \mathrm{mg}$ dietary lycopene per $d$ (averaging the first 5 weeks of $24 \mathrm{~h}$ recalls during the intervention period) was used to divide the intervention group into moderately and highly adherent men for analysis of behaviour model characteristics. Due to small sample size, ANOVA was used to assess differences between moderately and highly adherent men in the intervention and control groups. Simple correlation or linear modelling was also used to explore factors that were associated with more or less adherence using three outcome variables: weekly servings of TP and dietary lycopene and plasma lycopene concentrations for the entire intervention group. All possible impediments and incentives from the weekly telephone calls were collected for the intervention group, then coded and frequencies by week were tabulated. The values are presented as means and standard deviations and statistical significance is based on a $95 \%$ CI $(P<0 \cdot 05)$.

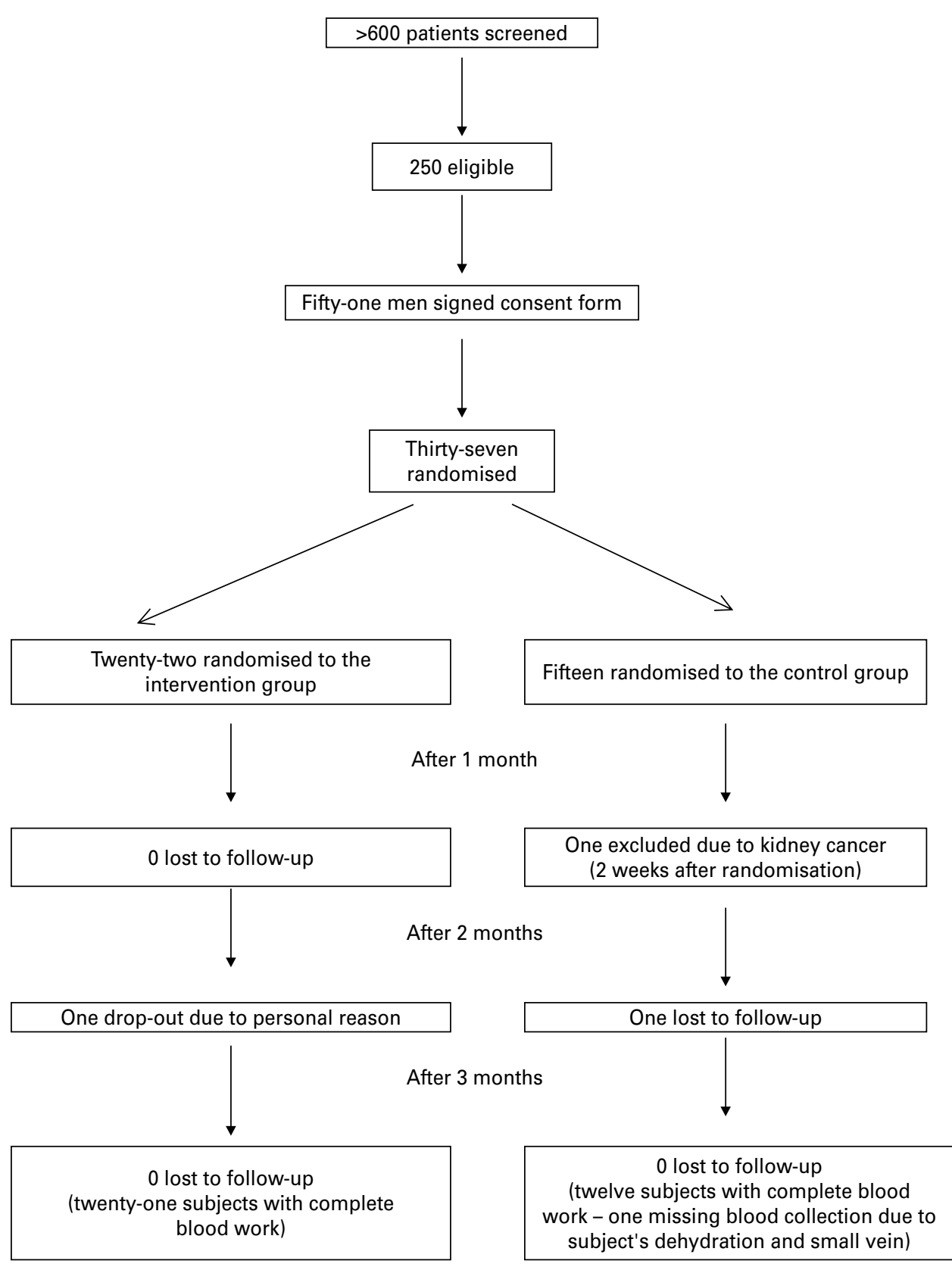

Fig. 1. Details of subject recruitment and withdrawal. 


\section{Results}

\section{Participant characteristics}

Of the fifty-one subjects who were enrolled at study entry, forty subjects (73\%) who participated in the run-in period were randomised into the main study (Fig. 1). Table 1

Table 1. Baseline characteristics of the study group

(Mean values and standard deviations; number of subjects and percentages)

\begin{tabular}{|c|c|c|c|c|}
\hline \multirow[b]{2}{*}{ Demographic characteristics } & \multicolumn{2}{|c|}{$\begin{array}{l}\text { Intervention } \\
\text { group }(n 22)\end{array}$} & \multicolumn{2}{|c|}{$\begin{array}{c}\text { Control } \\
\text { group }(n 15)\end{array}$} \\
\hline & $n$ & $\%$ & $n$ & $\%$ \\
\hline \multicolumn{5}{|l|}{ Age (years) } \\
\hline Mean & \multicolumn{2}{|c|}{$66 \cdot 2$} & \multicolumn{2}{|c|}{$68 \cdot 4$} \\
\hline SD & \multirow{2}{*}{\multicolumn{2}{|c|}{$7 \cdot 2$}} & \multicolumn{2}{|c|}{7.44} \\
\hline \multicolumn{3}{|l|}{ Serum PSA baseline $(\mathrm{ng} / \mathrm{ml})$} & & \\
\hline Mean & \multicolumn{2}{|c|}{$8 \cdot 0$} & \multicolumn{2}{|c|}{$8 \cdot 3$} \\
\hline SD & \multirow{2}{*}{\multicolumn{2}{|c|}{$4 \cdot 8$}} & \multicolumn{2}{|c|}{$8 \cdot 0$} \\
\hline \multicolumn{3}{|l|}{ Height $(\mathrm{cm})$} & & \\
\hline Mean & \multicolumn{2}{|c|}{$177 \cdot 9$} & \multicolumn{2}{|c|}{174.8} \\
\hline SD & \multirow{2}{*}{\multicolumn{2}{|c|}{8.5}} & \multicolumn{2}{|c|}{$5 \cdot 2$} \\
\hline \multicolumn{3}{|l|}{ Weight (kg) } & & \\
\hline Mean & \multirow{2}{*}{\multicolumn{2}{|c|}{$\begin{array}{c}93.9^{*} \\
14 \cdot 4\end{array}$}} & \multicolumn{2}{|c|}{$80 \cdot 7$} \\
\hline SD & & & & .2 \\
\hline BMI $\left(\mathrm{kg} / \mathrm{m}^{2}\right)$ & & & & \\
\hline Mean & & $7^{\star}$ & & .4 \\
\hline SD & & 3 & & 1 \\
\hline Marital status & & & & \\
\hline Married & 8 & $36 \cdot 36$ & 7 & $46 \cdot 67$ \\
\hline Others & 14 & 63.64 & 8 & $53 \cdot 33$ \\
\hline How many people in household & & & & \\
\hline$\leq 2$ People & 17 & $77 \cdot 27$ & 11 & 77.33 \\
\hline$>2$ People & 5 & $22 \cdot 73$ & 4 & $26 \cdot 67$ \\
\hline Education & & & & \\
\hline$\leq$ High school diploma & 6 & $27 \cdot 27$ & 8 & $53 \cdot 33$ \\
\hline > High school diploma & 16 & $72 \cdot 73$ & 7 & 46.67 \\
\hline Smoking experience & & & & \\
\hline Non-smoker & 15 & $68 \cdot 18$ & 11 & 73.33 \\
\hline Current smoker & 7 & 31.82 & 4 & $26 \cdot 67$ \\
\hline Physically active & & & & \\
\hline$<1 \mathrm{~h} /$ week & 11 & $50 \cdot 00$ & 6 & $40 \cdot 00$ \\
\hline Over $1 \mathrm{~h} /$ week & 11 & $50 \cdot 00$ & 9 & $60 \cdot 00$ \\
\hline Money security & & & & \\
\hline Limited money to purchase food & 12 & 54.55 & 11 & 73.33 \\
\hline No limitation of food purchasing & 10 & 45.45 & 4 & $26 \cdot 67$ \\
\hline Food security & & & & \\
\hline Enough food & 15 & $68 \cdot 18$ & 11 & 73.33 \\
\hline Limited food & 7 & 31.82 & 4 & $26 \cdot 67$ \\
\hline Meal cooking & & & & \\
\hline By myself & 17 & $72 \cdot 27$ & 10 & $66 \cdot 67$ \\
\hline By other & 5 & 23.73 & 5 & 33.33 \\
\hline Eat-out per week & & & & \\
\hline 0 & 5 & $22 \cdot 73$ & 5 & $33 \cdot 33$ \\
\hline 1 & 8 & $36 \cdot 36$ & 4 & $26 \cdot 67$ \\
\hline$\geq 2$ & 9 & 40.91 & 6 & $40 \cdot 00$ \\
\hline Food shopping & & & & \\
\hline Myself & 14 & 63.64 & 11 & $73 \cdot 33$ \\
\hline Others & 8 & $36 \cdot 36$ & 4 & $26 \cdot 67$ \\
\hline Menu choice & & & & \\
\hline Rare & 5 & 22.73 & 4 & $26 \cdot 67$ \\
\hline Sometimes & 5 & $22 \cdot 73$ & 2 & $26 \cdot 67$ \\
\hline Every time & 12 & 54.55 & 9 & $60 \cdot 00$ \\
\hline
\end{tabular}

PSA, prostate-specific antigen.

* There were significant group differences for body weight and BMI $(P<0.01$, $P<0.05$, respectively, $t$ test). However, there were no significant group differences for any of the other variables $\left(P>0.05, t\right.$ test or $\chi^{2}$ test). shows descriptive statistics for clinical, demographic and behavioural variables. The mean age at study entry was $67 \cdot 1$ years (range 51-83 years). The intervention group mean body weight was significantly greater $(94 \mathrm{~kg})$ than the control group $(81 \mathrm{~kg})(P=0.005)$, and they had a higher BMI $(P=0 \cdot 014)$. The distribution between different categories of marital status was roughly the same for the groups, with the preponderance being married or single, living in households of mostly one or two people. This was reflected in who made decisions about food eaten and who did the shopping in the household. In all, $70 \%$ of the men considered that they exercised great autonomy in their own food choices and food shopping, as about $70 \%$ of both groups prepared their meals. Care with money spent for food (62\%) and food insecurity $(30 \%)$ were issues for a significant number of men in the present study. Over $73 \%$ of both groups had eaten out less than twice per week, which may be associated with a need to budget carefully because of limited money.

\section{Participation and reporting adherence}

All subjects attended the orientation session to the study, a requirement for study participation. The mean of weekly telephone calls completed in the intervention group was 8.1 calls (67.5\% completed, ranging from four to thirteen calls during the 3 months). The study goal was $80 \%$ completion (9.6 phone calls). Reasons for lower-than-expected phone completion rates in a few subjects were as follows: being out of town or phone service disconnected due to financial difficulty. In the control group, a mean of 4.4 bi-weekly telephone calls were completed (73\%). The mean of collected $24 \mathrm{~h}$ recalls, including three during visits, was eleven recalls in the intervention group (ranged from seven to sixteen diet recalls) and 7.3 recalls in the control group (ranged from five to eleven diet recalls).

\section{Mean lycopene intake throughout the study}

As we gathered weekly diet recalls from the intervention group and bi-weekly diet recalls from the control group, we report monthly averaged nutrient intakes for the intervention and control group. Mean lycopene intake during the study period was $20.6(\mathrm{SD} 11.3) \mathrm{mg} / \mathrm{d}$ in the intervention group ( $424 \%$ increase from baseline intake, $P=0.0001$ for the between-group difference). There was also a mean increase in lycopene intake in the control group from 3.26 (SD 5.45) to $7 \cdot 25$ (SD 9.6$) \mathrm{mg} / \mathrm{d}$ (122\% increase from baseline intake), but the increase was not statistically significant (Table 2).

\section{Weekly tomato product intake for the intervention group}

Over $81 \%$ of the intervention group achieved the goal of more than five servings of TP/week (Table 2), increasing weekly TP intake from baseline values $(P<0 \cdot 0001)$ at 1 month, with no change in TP intake thereafter. The predominant TP chosen were V8 juice and tomato juice, according to weekly telephone reports (data not shown). 


\section{Plasma lycopene, other carotenoid and tocopherol concentrations over the 3-month period}

The adherence goal of a $50 \%$ increase in plasma lycopene concentration from baseline was met by the intervention group at 1 month $(53 \%, P=0.0028)$ but not at 3 months ( $40 \%, P=0.0162$ ). The decline between 1 and 3 months ( $8.7 \%$ decrease) was not statistically significant, and the overall increase was statistically significant $(P=0 \cdot 0013$, Table 3$)$. There was no control group increase in plasma lycopene concentration over the 3-month period. Association of reported lycopene intake in the intervention group with plasma lycopene levels was stronger at $1(r 0.43, P=0 \cdot 01)$ and 3 months ( $r 0.41, P=0.02)$, compared with baseline $(r-0.05, P=0.80)$. The mean biological half-life of lycopene in circulation using the most rigorous estimates ranges from 3 to $5 \mathrm{~d}$; hence, consistent consumption of TP during the intervention by the intervention group probably strengthened these associations ${ }^{(33,34)}$.

Plasma carotenoids, other than lycopene, $\alpha$-carotene and $\beta$-carotene concentrations (contained in TP), did not increase in the intervention group. Although there was a self-reported increase in dietary lutein + zeaxanthin in the control group, there were no changes in any of the plasma concentrations of carotenoids. If there had been increased intake of other fruits and vegetables in either group, as recommended as part of the AICR pamphlets, plasma concentrations of the other carotenoids, especially lutein + zeaxanthin, should have risen.

\section{Factors associated with adherence to increased tomato product intake}

Table 4 presents mean scores for behavioural factors often assessed as part of the social cognitive model, separately for highly and moderately adherent men in the intervention group, compared with the control group men. These behavioural factors were assessed before the intervention commenced, but all men had received their team assignment and had just viewed the orientation PowerPoint presentation designed for their respective group. While all groups scored high on knowledge of PC health and beliefs concerning foods that had been associated with reduced risk of cancer, the control group perceived more difficulty in adhering to their diet prescription, as measured by lower scores on the ease of adherence scale and higher scores on barriers to adherence scale compared with either intervention subgroup. Furthermore, barrier scores (e.g. storage, purchase effort, preparation issues, expense issues, not in usual diet, etc.) for the intervention group men were negatively associated with their 1 - and 3-month plasma lycopene concentrations ( $r$ $-0.37, P=0.024)$ and dietary lycopene $(r-0.49, P=0.022)$. The TP intake disadvantage score (e.g. too filling, unpleasant taste, intestinal discomfort, etc.) was also negatively associated with 3-month plasma lycopene concentrations $(r-0.37$, $P=0 \cdot 008)$.

\section{Intervention-related incentives and impediments}

Throughout the intervention period, men responded to open-ended questions concerning their incentives and 
Table 3. Physiological responses and upper gastrointestinal symptoms (UGIS) (Mean values and standard deviations)

\begin{tabular}{|c|c|c|c|c|c|c|c|c|c|c|c|c|}
\hline & \multicolumn{6}{|c|}{ Intervention group $(n 21)$} & \multicolumn{6}{|c|}{ Control group ( $n$ 12) } \\
\hline & \multicolumn{2}{|c|}{ Baseline } & \multicolumn{2}{|c|}{1 month } & \multicolumn{2}{|c|}{3 months } & \multicolumn{2}{|c|}{ Baseline } & \multicolumn{2}{|c|}{1 month } & \multicolumn{2}{|c|}{3 months } \\
\hline & Mean & SD & Mean & SD & Mean & SD & Mean & SD & Mean & SD & Mean & SD \\
\hline \multicolumn{13}{|l|}{ Physiological responses } \\
\hline Plasma lycopene $(\mu \mathrm{mol} / /)^{\star \star \star}$ & 0.45 & 0.22 & $0.69^{\star *}$ & 0.3 & $0.63^{\star *}$ & 0.4 & 0.45 & 0.24 & 0.41 & 0.2 & 0.41 & 0.2 \\
\hline Plasma $\alpha$-carotene $(\mu \mathrm{mol} / \mathrm{l})$ & 0.05 & 0.04 & $0.07^{\star}$ & 0.05 & $0.06^{\star}$ & 0.05 & 0.06 & 0.05 & 0.05 & 0.04 & 0.05 & 0.03 \\
\hline Plasma $\beta$-carotene $(\mu \mathrm{mol} / \mathrm{l})$ & 0.25 & 0.24 & $0.34^{*}$ & 0.23 & 0.28 & 0.25 & 0.32 & 0.25 & 0.27 & $0 \cdot 19$ & 0.29 & 0.24 \\
\hline Plasma $\beta$-cryptoxanthin $(\mu \mathrm{mol} / \mathrm{l})$ & 0.11 & 0.06 & 0.15 & 0.08 & 0.14 & 0.06 & 0.15 & 0.14 & 0.12 & $0 \cdot 1$ & $0 \cdot 10$ & 0.08 \\
\hline Plasma lutein + zeaxanthin $(\mu \mathrm{mol} / \mathrm{l})$ & 0.36 & 0.16 & 0.40 & 0.20 & 0.37 & 0.20 & 0.31 & 0.15 & 0.33 & 0.17 & 0.37 & $0 \cdot 18$ \\
\hline Plasma $\alpha$-tocopherol $(\mu \mathrm{mol} / \mathrm{l})$ & $27 \cdot 29$ & 9.53 & 28.52 & $7 \cdot 91$ & 26.93 & 8.53 & 27.47 & $10 \cdot 3$ & $27 \cdot 6$ & $15 \cdot 5$ & 24.07 & 7.99 \\
\hline Plasma $\gamma$-tocopherol $(\mu \mathrm{mol} / \mathrm{l})$ & $5 \cdot 22$ & 3.08 & $5 \cdot 11$ & 3.16 & $5 \cdot 70$ & $2 \cdot 89$ & 4.62 & 3.7 & 4.56 & $2 \cdot 90$ & 4.76 & 2.54 \\
\hline Plasma retinol $(\mu \mathrm{mol} / \mathrm{l})$ & 1.22 & 0.51 & $1.64^{\star}$ & 0.55 & $1.48^{\star}$ & 0.67 & 1.29 & 0.54 & 1.17 & 0.43 & $1 \cdot 22$ & 0.57 \\
\hline Total cholesterol (mg/l) & 1867 & 588 & 1762 & 387 & 1714 & 658 & 1886 & 381 & 1699 & 287 & 1708 & 331 \\
\hline \multicolumn{13}{|l|}{ Vital signs } \\
\hline Systolic blood pressure (mmHg) & $132 \cdot 6$ & $14 \cdot 8$ & $130 \cdot 8$ & $18 \cdot 1$ & $130 \cdot 1$ & $13 \cdot 7$ & $127 \cdot 2$ & $25 \cdot 4$ & 131.5 & 23.5 & $126 \cdot 2$ & 24.5 \\
\hline Diastolic blood pressure $(\mathrm{mmHg})$ & $76 \cdot 8$ & $9 \cdot 3$ & $76 \cdot 6$ & 11.4 & $75 \cdot 9$ & $8 \cdot 3$ & $80 \cdot 1$ & $10 \cdot 4$ & $77 \cdot 0$ & $10 \cdot 0$ & $75 \cdot 3$ & $10 \cdot 1$ \\
\hline Body weight $(\mathrm{kg})$ & $94 \cdot 2$ & $15 \cdot 2$ & 93.5 & $15 \cdot 7$ & 92.9 & $16 \cdot 8$ & $79 \cdot 0$ & $12 \cdot 2$ & 79.5 & $12 \cdot 8$ & 79.9 & $13 \cdot 6$ \\
\hline \multicolumn{13}{|l|}{ UGIS† } \\
\hline Epigastric pain & 0 & 0 & 0.03 & $0 \cdot 1$ & $0 \cdot 1$ & 0.2 & $0 \cdot 1$ & 0.2 & 0.2 & 0.3 & 0.2 & 0.4 \\
\hline Abdominal pain & 0.2 & 0.1 & $1 \cdot 1$ & 0.2 & 0.1 & 0.3 & 0.3 & 0.2 & 1.3 & $1 \cdot 1$ & 0.2 & 0.1 \\
\hline Heartburn & $0 \cdot 2$ & 0.5 & 0.3 & 0.7 & 0.2 & 0.4 & 0.4 & 0.6 & 0.3 & 0.6 & 0.2 & 0.4 \\
\hline Regurgitation & 0.1 & 0.3 & 0.1 & 0.3 & 0.2 & 0.4 & 0.1 & 0.4 & 0.2 & 0.4 & 0.2 & 0.6 \\
\hline Bloating & 0.5 & 0.8 & 0.7 & 1.0 & 0.5 & 0.7 & 0.5 & 0.7 & 0.5 & 0.7 & 0.5 & 0.8 \\
\hline Belching & 0.7 & 0.7 & 0.6 & 0.7 & 0.6 & 0.7 & 0.7 & 0.7 & 0.6 & 0.7 & 0.7 & 0.7 \\
\hline
\end{tabular}

Mean values were significantly different for within-group comparisons: ${ }^{*} P<0.05,{ }^{* *} P<0.001$

(

†UGIS were scored $0-6$, where 0 meant 'no complaints' and 6 represented the worst possible severity of that symptom. 
Table 4. Scores of behaviour model components by lycopene intake of highly and moderately adherent intervention participants and control participants

(Mean values with their standard errors)

\begin{tabular}{|c|c|c|c|c|c|c|}
\hline \multirow[b]{2}{*}{ Dietary lycopene and behaviour scores } & \multicolumn{2}{|c|}{$\begin{array}{l}\text { Intervention } \\
\geq 18 \mathrm{mg} / \mathrm{d} \\
(n 13) \dagger\end{array}$} & \multicolumn{2}{|c|}{$\begin{array}{c}\text { Intervention } \\
\leq 18 \mathrm{mg} / \mathrm{d} \\
\quad(n 8)\end{array}$} & \multicolumn{2}{|c|}{ Control ( $n$ 12) } \\
\hline & Mean & SEM & Mean & SEM & Mean & SEM \\
\hline \multicolumn{7}{|l|}{ Mean dietary lycopeneł } \\
\hline Baseline $(\mathrm{mg} / \mathrm{d})$ & 9.4 & $3 \cdot 1$ & $5 \cdot 9$ & $2 \cdot 0$ & 6.5 & 2.9 \\
\hline $1-5$ weeks $(\mathrm{mg} / \mathrm{d})$ & $27 \cdot 2$ & $2 \cdot 7$ & 13.4 & $1 \cdot 3$ & $6 \cdot 0$ & $1 \cdot 7$ \\
\hline $\begin{array}{l}\text { Dietary cancer prevention belief scores (eleven-item } \\
\text { scale, } 1-5 \text { points/item: descriptor = agreement) }\end{array}$ & 3.95 & $0 \cdot 18$ & $3 \cdot 89$ & $0 \cdot 14$ & $3 \cdot 71$ & 0.20 \\
\hline $\begin{array}{l}\text { Prostate cancer health belief scores (eight-item } \\
\text { scale, } 1-5 \text { points/item: descriptor }=\text { agreement) }\end{array}$ & $4 \cdot 28$ & $0 \cdot 15$ & $4 \cdot 22$ & 0.18 & $3 \cdot 76$ & $0 \cdot 28$ \\
\hline $\begin{array}{l}\text { Perceived ease of adherence to diet prescription } \\
\qquad(1-5 \text { points: descriptor, } 3=\text { neutral, } 4=\text { easy, } 5=\text { extremely easy) }\end{array}$ & 4.62 & 0.14 & $4 \cdot 50$ & 0.19 & 3.08 ** & 0.31 \\
\hline $\begin{array}{l}\text { Intention to adhere to diet prescription } \\
\qquad(1-5 \text { points: descriptor, } 4=\text { will try, } 5=\text { definitely will) }\end{array}$ & $5 \cdot 00$ & 0 & $5 \cdot 00$ & $0 \cdot 13$ & 4.90 & $0 \cdot 15$ \\
\hline $\begin{array}{l}\text { Perceived advantages of adherence (nine-item scale, } \\
\quad 1-5 \text { points/item: descriptor = importance) }\end{array}$ & $4 \cdot 24$ & 0.24 & $4 \cdot 07$ & 0.45 & $4 \cdot 19$ & 0.22 \\
\hline $\begin{array}{l}\text { Perceived disadvantages of adherence (six-item scale, } \\
\qquad 1-5 \text { points/item: descriptor }=\text { importance) }\end{array}$ & 3.02 & 0.34 & $3 \cdot 19$ & 0.40 & $3 \cdot 61$ & 0.31 \\
\hline $\begin{array}{l}\text { Personal barriers to adherence (ten-item scale, } \\
\qquad 1-5 \text { points/item: descriptor }=\text { importance) }\end{array}$ & $2 \cdot 09$ & 0.39 & $2 \cdot 70$ & 0.27 & $3 \cdot 30^{\star}$ & 0.29 \\
\hline Social support score (eight-item scale, $1-5$ points/item; descriptor = support) & 3.84 & 0.24 & 3.56 & 0.43 & 3.36 & 0.25 \\
\hline
\end{tabular}

Mean values between-group were significantly different for the control group: * $P=0.04,{ }^{* *} P \leq 0.0001$.

† Intervention group was divided into highly and moderately adherent men using a dietary lycopene cut point of $18 \mathrm{mg} / \mathrm{d}$ averaged over the first $5 \mathrm{meeks}$ of the intervention. $\ddagger$ Mean of four baseline $24 \mathrm{~h}$ diet recalls and mean of five weekly $24 \mathrm{~h}$ diet recalls during intervention period.

impediments. The orientation session appeared to be motivational, as many of the intervention group subjects mentioned it to be the source of their adherence. Many of the intervention group subjects volunteered that they liked the newsletter and tried to cook tomato dishes from newsletter recipes (fourteen responded out of twenty-four subjects, 58\%). Although both control and intervention groups were introduced to the AICR cancer prevention diet during their orientations and by the AICR booklets, no specific or ongoing counselling was provided for this dietary change.

The incentives for TP consumption tended to be consistent from one call to the next for each participant. Most subjects reported the consumption of a TP on their $24 \mathrm{~h}$ diet recall, and weekly consumption mostly met the goal of more than five servings per week; hence, weekly goal setting based on reported impediments was not necessary. Table 5 presents the weekly frequency of self-reported incentives and impediments to the previous day's consumption of a TP, collected as part of the $24 \mathrm{~h}$ diet recall process. Concern over prostate health was the most consistent, and remained the most predominant incentive throughout the study. Although many men volunteered that they liked tomatoes at the beginning of the study, this incentive abruptly decreased after week 6, as well as another incentive, study participation, which dropped by week 9. Family member support (principally wives) was an important incentive for a few men, especially in the middle of the study. The media exposure was described as a segment by $\mathrm{Dr} \mathrm{Oz}$ on the Oprah Winfrey Show that featured tomato

Table 5. Frequency of self-reported incentives and impediments to previous day's consumption of tomato products (TP) by men in the intervention group

\begin{tabular}{|c|c|c|c|c|c|c|c|c|}
\hline \multirow[b]{2}{*}{ Week } & \multicolumn{5}{|c|}{ Incentives } & \multicolumn{3}{|c|}{ Impediments } \\
\hline & Prostate health & Like tomatoes & Study participant & Social support & Media exposure & Cupboard bare of TP & Forgot & Poor appetite \\
\hline 1 & 6 & 7 & 6 & 4 & 0 & 2 & 0 & 0 \\
\hline 2 & 9 & 8 & 7 & 1 & 1 & 1 & 0 & 0 \\
\hline 3 & 9 & 5 & 5 & 1 & 1 & 2 & 0 & 1 \\
\hline 4 & 9 & 7 & 3 & 1 & 1 & 2 & 0 & 0 \\
\hline 5 & 8 & 4 & 2 & 6 & 1 & 0 & 1 & 0 \\
\hline 6 & 9 & 5 & 4 & 3 & 3 & 2 & 0 & 1 \\
\hline 7 & 10 & 2 & 6 & 3 & 1 & 0 & 1 & 0 \\
\hline 8 & 7 & 3 & 6 & 3 & 0 & 0 & 1 & 0 \\
\hline 9 & 10 & 1 & 2 & 3 & 0 & 1 & 1 & 0 \\
\hline 10 & 10 & 1 & 1 & 2 & 0 & 1 & 0 & 0 \\
\hline 11 & 9 & 1 & 1 & 1 & 0 & 0 & 1 & 0 \\
\hline 12 & 5 & 0 & 2 & 0 & 0 & 1 & 1 & 0 \\
\hline
\end{tabular}


consumption for the prevention of PC. The number of cited impediments was much lower than reported incentives, because there were far fewer occasions when the men had not consumed a TP on the day when the $24 \mathrm{~h}$ recall was taken. TP availability at the time of food preparation and forgetting are likely to play an important role in a larger, lessadherent group of men.

\section{Adverse effects of eating daily tomato products}

A common belief that dishes containing TP cause gastric distress and increase in $\mathrm{Na}$, saturated fat and cholesterol intake, leading to higher blood pressure and plasma cholesterol, prompted us to explore these issues, as well as diet displacement caused by the aggressive inclusion of a single food class.

\section{Dietary nutrient displacement}

Energy intake for the intervention group was surprisingly lower than the control group throughout the study period (Table 2). However, there were no statistically significant changes within and between groups over the 3-month period $(P=0.883)$. As the intervention group had higher BMI and percentage body fat and reported lower exercise levels, a combination of lower energy needs and probably greater underreporting of food intake could have contributed to the discrepancy. As energy intakes were different for the intervention and control groups, diet quality was assessed after energy adjustment. The intervention group did not increase saturated fat intake $(P=0.10)$ or cholesterol intake $(P=0.002)$, which showed a downwards trend, compared with the control group over the 3-month period (Table 2). Changes in foodbased, non-discretionary $\mathrm{Na}$ intake are not shown because of validity concerns ${ }^{(35)}$, although intakes averaged over double the recommended $\mathrm{Na}$ requirement ${ }^{(36)}$ for both groups.

\section{Physiological parameters}

As noted previously, the intervention group had a higher mean body weight at the beginning of the study and maintained this difference throughout. They experienced a slight decrease in body weight by 3 months, but the change was statistically insignificant (Table 3). There was no difference in total plasma cholesterol concentration between the intervention and control group at any time point, i.e. at 1 and 3 months ( $P=0.51$ and 0.81 , respectively). Total plasma cholesterol concentration decreased within each group over the 3-month period, but the decrement in the intervention group was uncertain $(P=0 \cdot 061)$. There were no changes in systolic blood pressure and diastolic blood pressure for either group over the course of the study (Table 3 ).

Although the present study was not sufficiently powered to determine that no changes occurred in blood pressure and plasma cholesterol concentrations, the null results are consistent with the dietary reports.

\section{Gastrointestinal symptoms}

There were no between-group differences in upper gastrointestinal symptoms. Both groups initially reported an increase in abdominal pain at 1 month $(P=0.06)$, but it appeared to be resolved by 3 -months of the study $(P=0 \cdot 18$, Table 3$)$.

\section{Discussion}

The present preliminary study demonstrated that AA men with low socio-economic status at risk for PC increased their lycopene intake through a self-selected diet by four-fold (to $20.6 \mathrm{mg} / \mathrm{d}$ ) during a 3-month period. Plasma lycopene concentrations in the intervention group rose from 0.45 to $0.69 \mu \mathrm{mol} / 1$ (53\% increase) at 1 month, which was consistent with their self-reported intake, and the slight decrement (to 0.63 $\mu \mathrm{mol} / \mathrm{l})$ at 3 months mirrored their reported decrement in lycopene intake at 3 months. Baseline plasma lycopene values were similar to those reported in other studies, e.g. for AA men (from 0.27 to $0.41 \mu \mathrm{mol} / \mathrm{l}$ ), regardless of ethnicity (from 0.22 to $0.73 \mu \mathrm{mol} / 1)^{(37-44)}$. As expected, this plasma lycopene increment was not as great as we reported for mostly AA men with PC recruited from the same clinic, who received $30 \mathrm{mg} / \mathrm{d}$ of lycopene as daily tomato pasta entrées for 3 weeks before surgery (0.64-1.26 $\mu \mathrm{mol} / \mathrm{l}$; $97 \%$ increase $)^{(20)}$. The control group reported progressive increases in dietary carotenoids (lycopene $122 \%$, NS and $\beta$-carotene $361 \%, \quad P=0.09)$ and lutein + zeaxanthin $(509 \%, P=0.01)$ (Table 2), while there was no rise in their plasma carotenoids (Table 3), indicating a possible intention to increase fruit and vegetable intake, as prescribed by the AICR diet. The intervention group reported no dietary increase in carotenoids other than lycopene. Even though they also were encouraged to follow the AICR diet, they chose to focus on the TP assignment. Parsons et al. ${ }^{(45)}$ promoted increased fruit and vegetable consumption via telephone-based counselling to forty-three PC patients and found the following 6-month increments in plasma carotenoids: $\alpha$-carotene $37 \%, \quad \beta$-carotene $32 \%$, lutein + zeaxanthin 23\%, lycopene $30 \%$ (despite a reported $265 \%$ increase in TP intake) and total carotenoids $25 \%$. The AICR cancer prevention diet prescription may have been too complex to adopt without specific counselling in our group of men.

We explored the effects of social cognitive model domains for behaviour change on the level of adherence within and between the two groups, using lycopene intake, TP intake and plasma lycopene concentrations as measures of adherence. The usual factors such as knowledge, intention and self-efficacy were less predictive in our subjects, because all scored highly on these scales, possibly because they all had just experienced a well-received presentation that outlined prostate health and dietary factors for cancer prevention. The most predictive of subsequent adherence were scales that explored the importance of various barriers to adherence, along with a list of disadvantages as a separate scale. Not only did the control group have higher scores on these scales, the intervention group scores were inversely correlated with their lycopene intake and plasma lycopene concentrations. 
Carcaise-Edinboro et al. ${ }^{(46)}$ promoted, through pamphlets and a few telephone calls, a cancer prevention diet, in 754 lowincome, low-literacy patients, of whom 36.8\% were AfricanAmerican. Despite a two-fold increase in knowledge and intention to increase fruit and vegetable consumption among AA men and women, their diets did not change. Many investigators have concluded that understanding specific barriers in each population and actively addressing them should improve adherence $^{(47-51)}$

We proposed that incentives and impediments to adherence would arise in the context of now-time decision making, would be temporally unstable and so could be better remembered for the previous day. These were assessed only in intervention subjects at the time of their $24 \mathrm{~h}$ recalls. Incentives predominated over impediments, because most of the intervention subjects adhered to their diet prescription with respect to TP consumption, and incentives were remarkably stable from week to week. However, liking tomatoes and study participation lost their incentive appeal by the sixth and ninth week of the study, respectively, while prostate health remained important throughout the study. The only study that evaluated dietary pre- and post-intervention shifts in barriers was a Scottish fruit and vegetable intervention ${ }^{(52)}$. The number of visits to stores became a more prominent barrier during the intervention, while other barriers became less important $^{(52)}$. Two exercise intervention studies also found shifts in barrier importance and type as the interventions proceeded $^{(53,54)}$.

We found few diet shifts or adverse effects resulting from a fairly large increase in TP consumption in the intervention group. Energy under-reporting was evident in the intervention group men who had higher BMI, a commonly reported finding ${ }^{(55,56)}$. We chose to display reported energy intakes instead of using the classical Goldberg adjustment ${ }^{(57)}$ because: (1) several of our subjects in each group indicated limited food supply (32\% intervention, $27 \%$ control; Table 1); (2) an inspection of individual recalls for 'under-reporters' showed consistently low intakes or sporadically very low intakes on single days; (3) we were interested in changes in TP and fruits and vegetables rather than the foods that are usually forgotten, such as snacks. Our personal experience with this population is that food shortages are often temporary and may not be reflected in BMI. An exploration of those who lost weight during the study could not explain reported low energy intakes.

We saw no change in both systolic and diastolic blood pressure. A total of fifteen subjects in our intervention group were being treated for hypertension and they often forgot to take their medication. Contrary to the common advice to avoid TP to minimise gastric complaints, upper gastrointestinal symptoms did not change over the time of the study.

The present feasibility study had some limitations. First, the number of phone calls and collected diet recalls between groups was different because of the concern that the control group would increase their TP intake. As there was a negligible 'drop-in' effect in the control subjects, the number of contacts could be equalised in a larger study. Second, the sample size was small and groups were unequal in number to account for an estimated non-adherence rate of $40 \%$ in the intervention group. This rate was estimated from adherence rates in published fruit and vegetable intervention studies $^{(58-66)}$. As our AA participants were mostly successful in increasing their TP intake, we gained little insight into the impediments encountered in affecting a simple diet change.

\section{Conclusions}

The present study demonstrated that low-income AA men, who are at higher risk for PC, can successfully achieve their $\mathrm{TP}$ adherence goal with a corresponding rise in plasma lycopene concentrations. Increased $\mathrm{TP}$ consumption did not increase dietary cholesterol or saturated fat, which was consistent with no increase in blood pressure or plasma total cholesterol concentration. Although the control group had the same risk for PC and knew of the tomato intervention, they did not voluntarily 'drop-in' to the intervention arm of the study, while the intervention group appeared to ignore the AICR diet in favour of the single food recommendation.

The present whole-food intervention was sufficiently simple for successful participant adherence and enabled the determination of incentives and impediments to previous day compliance, while memories were fresh. Incentives, for the most part, were temporally stable, although the stability of impediments requires further investigation. The disadvantage and barriers category of the environmental domain of the social cognitive theoretical model of behaviour change was the most predictive of adherence, with the control group perceiving greater difficulty in adhering to the AICR diet recommendation In conclusion, single-food intervention studies may provide greater understanding of the dynamics of dietary adherence as well as improve adherence, both for longer intervention studies and as a strategy for achieving healthpromoting dietary patterns.

\section{Acknowledgements}

The authors acknowledge the contributions of the entire staff at the Jesse Brown Urology Clinic for their help on the present complex feasibility study. The study was funded by the Midwest Roybal Foundation, University of Illinois at Chicago, IL, USA. The contribution of authors are as follows: E. P. and P. E. B. designed the research; E. P., P. E. B. and M. S.-S. conducted the research; E. P., R. S. and Z. W. conducted recruitment; P. E. B. and V. L. F. planned and performed orientation sessions; E. P. and M. S.-S. performed plasma laboratory analyses; E. P. performed statistical data analyses; E. P. and P. E. B. wrote the paper; E. P. had primary responsibility for final content. All authors read and approved the final manuscript. The authors declare no conflicts of interest.

\section{References}

1. Lanza E, Schatzkin A, Daston C, et al. (2001) Implementation of a 4-y, high-fiber, high-fruit-and-vegetable, low-fat dietary intervention: results of dietary changes in the Polyp Prevention Trial. Am J Clin Nutr 74, 387-401. 
2. Wanke KL, Daston C, Slonim A, et al. (2007) Adherence to the polyp prevention trial dietary intervention is associated with a behavioral pattern of adherence to nondietary trial requirements and general health recommendations. $J$ Nutr 137, 391-398.

3. Ammerman AS, Lindquist CH, Lohr KN, et al. (2002) The efficacy of behavioral interventions to modify dietary fat and fruit and vegetable intake: a review of the evidence. Prev Med 35, 25-41.

4. Gadson SL (2006) The third world health status of black American males. J Natl Med Assoc 98, 488-491.

5. Witt DK (2006) Health disparities in African American males. Prim Care 33, 35-43.

6. Williamson DA, Anton SD, Han $\mathrm{H}$, et al. (2010) Adherence is a multi-dimensional construct in the POUNDS LOST trial. J Behav Med 33, 35-46.

7. Logan KJ, Woodside JV, Young IS, et al. (2010) Adoption and maintenance of a Mediterranean diet in patients with coronary heart disease from a Northern European population: a pilot randomised trial of different methods of delivering Mediterranean diet advice. J Hum Nutr Diet 23, 30-37.

8. Swenson KK, Nissen MJ \& Henly SJ (2010) Physical activity in women receiving chemotherapy for breast cancer: adherence to a walking intervention. Oncol Nurs Forum 37, 321-330.

9. Two Feathers J, Kieffer E, Palmisano G, et al. (2005) Racial and Ethnic Approaches to Community Health (REACH) Detroit partnership: improving diabetes-related outcomes among African American and Latino adults. Am J Public Health 95, 1552-1560.

10. Becker DM, Yanek LR, Johnson WR, et al. (2005) Impact of a community-based multiple risk factor intervention on cardiovascular risk in black families with a history of premature coronary disease. Circulation 111, 1298-1304.

11. Svetkey LP, Erlinger TP, Vollmer WM, et al. (2005) Effect of lifestyle modifications on blood pressure by race, sex, hypertension status, and age. J Hum Hypertens 19, 21-31.

12. Resnicow K, Campbell MK, Carr C, et al. (2004) Body and soul. A dietary intervention conducted through AfricanAmerican churches. Am J Prev Med 27, 97-105.

13. Parra-Medina D, D'Antonio A, Smith SM, et al. (2004) Successful recruitment and retention strategies for a randomized weight management trial for people with diabetes living in rural, medically underserved counties of South Carolina: the POWER study. J Am Diet Assoc 104, 70-75.

14. Robinson SB, Ashley M \& Haynes MA (1996) Attitudes of African-Americans regarding prostate cancer trials. J Community Health 21, 77-87.

15. Shankar S, Selvin S \& Alberg AJ (2002) Perceptions of cancer in an African-American community: a focus group report. Ethn Dis 12, 276-283.

16. Randall V (1996) Slavery, segregation and racism: trusting the healthcare systems ain't always easy! An AfricanAmerican perspective on bioethics. St Louis Univ Public Law Rev 15, 191-235.

17. Meade CD, Calvo A, Rivera MA, et al. (2003) Focus groups in the design of prostate cancer screening information for Hispanic farmworkers and African American men. Oncol Nurs Forum 30, 967-975.

18. Surveillance Epidemiology and End Results. SEER Cancer Statistics Review 1975-2007. http://seer.cancer.gov/csr/ 1975_2007/ (accessed 12 June 2010).

19. Kavanaugh CJ, Trumbo PR \& Ellwood KC (2007) The U.S. Food and Drug Administration's evidence-based review for qualified health claims: tomatoes, lycopene, and cancer. J Natl Cancer Inst 99, 1074-1085.
20. Chen L, Stacewicz-Sapuntzakis M, Duncan C, et al. (2001) Oxidative DNA damage in prostate cancer patients consuming tomato sauce based entrees as a whole food intervention. J Natl Cancer Inst 93, 1872-1879.

21. Giovannucci E, Ascherio A, Rimm EB, et al. (1995) Intake of carotenoids and retinol in relation to risk of prostate cancer. J Natl Cancer Inst 87, 1767-1776.

22. Boileau TW, Liao Z, Kim S, et al. (2003) Prostate carcinogenesis in $N$-methyl- $N$-nitrosourea (NMU)-testosterone-treated rats fed tomato powder, lycopene, or energy-restricted diets. J Natl Cancer Inst 95, 1578-1586.

23. Bandura A (2004) Health promotion by social cognitive means. Health Educ Behav 31, 143-164.

24. Glanz K, Rimer BK \& Viswanath K (editors) (2008) Health Behavior and Health Education: Theory, Research, and Practice, 4th ed. San Francisco, CA: Jossey-Bass.

25. Conway JM, Ingwersen LA, Vinyard BT, et al. (2003) Effectiveness of the US Department of Agriculture 5-step multiple-pass method in assessing food intake in obese and nonobese women. Am J Clin Nutr 77, 1171-1178.

26. Conway JM, Ingwersen LA \& Moshfegh AJ (2004) Accuracy of dietary recall using the USDA five-step multiple-pass method in men: an observational validation study. $J \mathrm{Am}$ Diet Assoc 104, 595-603.

27. Stacewicz-Sapuntzakis M, Bowen PE, Kikendall JW, et al. (1987) Simultaneous determination of serum retinol and various carotenoids: their distribution in middle aged men and women. J Micronutr Anal 3, 27-45.

28. Duewer DL, Kline MC, Sharpless KE, et al. (2000) NIST micronutrients measurment quality assurance program: characterizing individual participant measurement performance over time. Anal Chem 72, 3611-3619.

29. Bovenschen HJ, Janssen MJ, van Oijen MG, et al. (2006) Evaluation of a gastrointestinal symptoms questionnaire. Dig Dis Sci 51, 1509-1515.

30. Bowen P, Chen L, Stacewicz-Sapuntzakis M, et al. (2002) Tomato sauce supplementation and prostate cancer: lycopene accumulation and modulation of biomarkers of carcinogenesis. Exp Biol Med 227, 886-893.

31. Prasad GV, Huang M, Nash MM, et al. (2005) Role of dietary salt intake in posttransplant hypertension with tacrolimusbased immunosuppression. Transplant Proc 37, 1896-1897.

32. He J, Ogden LG, Bazzano LA, et al. (2002) Dietary sodium intake and incidence of congestive heart failure in overweight US men and women: first National Health and Nutrition Examination Survey Epidemiologic Follow-up Study. Arch Intern Med 162, 1619-1624.

33. Gustin DM, Rodvold KA, Sosman JA, et al. (2004) Singledose pharmacokinetic study of lycopene delivered in a well-defined food-based lycopene delivery system (tomato paste-oil mixture) in healthy adult male subjects. Cancer Epidemiol Biomarkers Prev 13, 850-860.

34. Ross AB, Vuong le T, Ruckle J, et al. (2011) Lycopene bioavailability and metabolism in humans: an accelerator mass spectrometry study. Am J Clin Nutr 93, 1263-1273.

35. Mattes RD \& Donnelly D (1991) Relative contributions of dietary sodium sources. J Am Coll Nutr 10, 383-393.

36. Cogswell ME (2011) Usual sodium intakes compared with current dietary guidelines, United States, 2005-2008. Morbidity and Mortality Weekly 60, 1413-1417.

37. Lucier G, Lin BH, Allshouse J, et al. (2000) Factors affecting tomato consumption in the United States. http://www.ers. usda.gov/Briefing/consumption/gallery/TomatoConsumption. pdf. p 26-32 (accessed 14 February 2006).

38. Resnicow K, Odom E, Wang T, et al. (2000) Validation of three food frequency questionnaires and 24-hour recalls 
with serum carotenoid levels in a sample of African-American adults. Am J Epidemiol 152, 1072-1080.

39. Vogt TM, Mayne ST, Graubard BI, et al. (2002) Serum lycopene, other serum carotenoids, and risk of prostate cancer in US Blacks and Whites. Am J Epidemiol 155, 1023-1032.

40. Ford ES (2000) Variations in serum carotenoids concentrations among United States adults by ethnicity and sex. Ethn Dis 10, 208-217.

41. Rissanen T, Voutilainen S, Nyyssonen K, et al. (2000) Low plasma lycopene concentration is associated with increased intima-media thickness of the carotid artery wall. Arterioscler Thromb Vasc Biol 20, 2677-2681.

42. Wu K, Erdman JW Jr, Schwartz SJ, et al. (2004) Plasma and dietary carotenoids, and the risk of prostate cancer: a nested case-control study. Cancer Epidemiol Biomarkers Prev 13, 260-269.

43. Freeman VL, Meydani M, Yong S, et al. (2000) Prostatic levels of tocopherols, carotenoids, and retinol in relation to plasma levels and self-reported usual dietary intake. Am J Epidemiol 151, 109-118.

44. Lu QY, Hung JC, Heber D, et al. (2001) Inverse associations between plasma lycopene and other carotenoids and prostate cancer. Cancer Epidemiol Biomarkers Prev 10, 749-756.

45. Parsons JK, Newman VA, Mohler JL, et al. (2008) Dietary modification in patients with prostate cancer on active surveillance: a randomized, multicenter feasibility study. BJU Int 101, 1227-1231.

46. Carcaise-Edinboro P, McClish D, Kracen AC, et al. (2008) Fruit and vegetable dietary behavior in response to a low-intensity dietary intervention: the rural physician cancer prevention project. J Rural Health 24, 299-305.

47. Nagelkerk J, Reick K \& Meengs L (2006) Perceived barriers and effective strategies to diabetes self-management. $J$ Adv Nurs 54, 151-158.

48. Vijan S, Stuart NS, Fitzgerald JT, et al. (2005) Barriers to following dietary recommendations in type 2 diabetes. Diabet Med 22, 32-38.

49. Lennie TA, Worrall-Carter L, Hammash M, et al. (2008) Relationship of heart failure patients' knowledge, perceived barriers, and attitudes regarding low-sodium diet recommendations to adherence. Prog Cardiovasc Nurs 23, 6-11.

50. Serour M, Alqhenaei H, Al-Saqabi S, et al. (2007) Cultural factors and patients' adherence to lifestyle measures. $\mathrm{Br} \mathrm{J}$ Gen Pract 57, 291-295.

51. Goebel LJ, Bailony F, Khattak AJ, et al. (2006) Physician and patient barriers to adherence with cholesterol guidelines. W V Med J 102, 23-26.

52. Anderson AS, Cox DN, McKellar S, et al. (1998) Take Five, a nutrition education intervention to increase fruit and vegetable intakes: impact on attitudes towards dietary change. Br J Nutr 80, 133-140.

53. Courneya KS, Friedenreich CM, Quinney HA, et al. (2005) A longitudinal study of exercise barriers in colorectal cancer survivors participating in a randomized controlled trial. Ann Behav Med 29, 147-153.

54. Williams BR, Bezner J, Chesbro SB, et al. (2006) The effect of a walking program on perceived benefits and barriers to exercise in postmenopausal African American women. $J$ Geriatr Phys Ther 29, 43-49.

55. Shahar DR, Yu B, Houston DK, et al. (2010) Misreporting of energy intake in the elderly using doubly labeled water to measure total energy expenditure and weight change. J Am Coll Nutr 29, 14-24.

56. Tooze JA, Subar AF, Thompson FE, et al. (2004) Psychosocial predictors of energy underreporting in a large doubly labeled water study. Am J Clin Nutr 79, 795-804.

57. Tooze JA, Krebs-Smith SM, Troiano RP, et al. (2012) The accuracy of the Goldberg method for classifying misreporters of energy intake on a food frequency questionnaire and 24-h recalls: comparison with doubly labeled water. Eur J Clin Nutr 66, 569-576.

58. Marcus AC, Morra M, Rimer BK, et al. (1998) A feasibility test of a brief educational intervention to increase fruit and vegetable consumption among callers to the cancer information service. Prev Med 27, 250-261.

59. Kristal AR, Curry SJ, Shattuck AL, et al. (2000) A randomized trial of a tailored, self-help dietary intervention: the Puget Sound Eating Patterns study. Prev Med 31, 380-389.

60. Marcus AC, Heimendinger J, Wolfe P, et al. (2001) A randomized trial of a brief intervention to increase fruit and vegetable intake: a replication study among callers to the CIS. Prev Med 33, 204-216.

61. Delichatsios HK, Hunt MK, Lobb R, et al. (2001) EatSmart: efficacy of a multifaceted preventive nutrition intervention in clinical practice. Prev Med 33, 91-98.

62. Glasgow RE, Toobert DJ, Hampson SE, et al. (2002) Implementation, generalization and long-term results of the "choosing well" diabetes self-management intervention. Patient Educ Couns 48, 115-122.

63. Kris-Etherton PM, Taylor DS, Smiciklas-Wright $\mathrm{H}$, et al. (2002) High-soluble fiber foods in conjunction with a telephone-based, personalized behavior change support service result in favorable changes in lipids and lifestyles after 7 weeks. J Am Diet Assoc 102, 503-510.

64. Pierce JP, Newman VA, Flatt SW, et al. (2004) Telephone counseling intervention increases intakes of micronutrientand phytochemical-rich vegetables, fruit and fiber in breast cancer survivors. J Nutr 134, 452-458.

65. Newman VA, Thomson CA, Rock CL, et al. (2005) Achieving substantial changes in eating behavior among women previously treated for breast cancer - an overview of the intervention. Am J Diet Assoc 105, 382-391.

66. Smith DE, Heckemeyer CM, Kratt PP, et al. (1997) Motivational interviewing to improve adherence to a behavioral weight-control program for older obese women with NIDDM. A pilot study. Diabetes Care 20, 52-54. 